\title{
Aproximações de Morin e Freire na busca da educação complexa e dialógica
}

\author{
Marida Aparecida Behrens ${ }^{*}$ \\ Edna Liz Prigol ${ }^{* *}$ \\ Ariana Cosme $e^{* * *}$
}

\section{Resumo}

Este artigo tem como foco as contribuições de Edgar Morin e Paulo Freire na educação e na formação de professores. O problema investigado foi: como os docentes que atuam na formação pedagógica dos professores universitários veem a pertinência de propor as concepções do paradigma da complexidade e da educação dialógica como pilares epistemológicos que sustentam a renovação da ação docente? Como objetivo, buscou-se investigar os construtos, saberes e práticas que caracterizam o paradigma da complexidade e a educação dialógica como abordagens inovadoras na reconstrução da prática docente. A pesquisa qualitativa, do tipo etnográfica, com procedimentos via netnografia, envolveu 13 professores portugueses e brasileiros, entrevistados de forma on-line. Os resultados apontam que os docentes acham relevante o acolhimento dos construtos

* Graduada em Pedagogia-UFPR. Mestre e Doutora em Educação pela Pontifica Universidade Católica de São Paulo PUCSP. Pós-doutora em Educação na Universidade do Porto-Portugal. Docente do Programa de Pós-Graduação em Educação da Pontifica Universidade Católica do Paraná. Pesquisadora do Conselho Nacional de Pesquisa (CNPq).Orcid http://orcid.org0000-00023446-2321 e.mail : Marildaab@gmail.com

** Graduada em Pedagogia (Tuiuti/PR). Mestre e Doutora em Educação PUCPR. Bolsista de estágio Pós-Doutoral (CAPES) na PUCPR. Pesquisadora no GRUPO PEFOP- PUCPR e no GEPEPECOE-UFPR. Orcid http:// orcid.org/0000-0002-7449-6622 e.mail: prigoledna@gmail.com

*** Graduada em Pedagogia. Pós doutora em Educação no PPGE da PUCPR. Doutora em Educação da Faculdade de Psicologia e Ciências da Educação da Universidade do Porto-Portugal. Professora na Pós- Graduação da Faculdade de Psicologia e Ciências da Educação da Universidade do Porto-Portugal. Orcid http://orcid.org/0000-0002-8194-5027 e.mail: ariana@fpce.up.pt. 
morinianos e freirianos como pilares epistemológicos para a reconstrução da prática pedagógica.

Palavras-chave: Morin. Freire. Paradigma da complexidade. Educação dialógica.

\section{Morin and Freire approximations in the search for complex and dialogic education}

\section{Abstract}

The article focuses on the contributions of Edgar Morin and Paulo Freire in teacher education and training. The problem investigated was: How do professors who work in the pedagogical training of university professors see the relevance of proposing the concepts of the paradigm of complexity and dialogic education as epistemological pillars that support the renewal of the teaching action? The objective was to: Investigate the constructs, knowledge and practices that characterize the paradigm of complexity and dialogic education as innovative approaches in the reconstruction of teaching practice. The qualitative research, of the ethnographic type, with procedures via netnography, involved 13 Portuguese and Brazilian teachers, interviewed online. The results show that teachers with expertise find the acceptance of Morinian and Freirian constructs relevant as epistemological pillars for the reconstruction of pedagogical practice.

Keywords: Morin. Freire. Complexity paradigm, dialogic education.

\section{Aproximaciones de Morin y Freire en la búsqueda de una educación compleja y dialógica}

\section{Resumen}

El artículo se centra en las contribuciones de Edgar Morin y Paulo Freire en la educación y en la formación docente. El problema investigado fue: Cómo los profesores que trabajan en la formación pedagógica de los profesores universitarios ven la relevancia de proponer los conceptos del paradigma de la complejidad y de la educación dialógica como pilares epistemológicos que sustentan la renovación de la acción docente? Como meta, se buscó: Investigar los constructos, los saberes y las prácticas que caracterizan el paradigma de la complejidad y la educación dialógica como enfoques innovadores en la reconstrucción de la práctica docente. La investigación cualitativa, del tipo etnográfico, con procedimientos vía netnografía, incluyó a 13 profesores portugueses y brasileños, entrevistados 
a través de internet. Los resultados muestran que los profesores con experiencia piensan que es relevante la multitud de los constructos morinianos y freirianos como pilares epistemológicos para la reconstrucción de la práctica pedagógica.

Palabras clave: Morin, Freire, paradigma de la complejidad, educación dialógica

\section{Introdução}

A investigação sobre educação dialógica desenvolvida pelo grupo Paradigmas Educacionais e Formação de Professores (PEFOP) envolveu uma pesquisa intitulada "Paradigma da complexidade e transdisciplinaridade como pilares epistemológicos para geração de construtos, saberes e práticas na formação pedagógica dos professores", financiada pelo Conselho Nacional de Desenvolvimento Científico e Tecnológico $(\mathrm{CNPq})$ e registrada no Diretório de Grupos de Pesquisa do Brasil da Plataforma Lattes. A referida pesquisa integra a linha de pesquisa Teoria e Prática Pedagógica na Formação de Professores do Programa de Pós-Graduação em Educação (PPGE) da Pontifícia Universidade Católica do Paraná (PUCPR). Ainda, foi sediada pela PUCPR, que coordena uma rede de pesquisa internacional composta por quatro grupos, contando com pesquisadores da própria instituição e da Universidade Federal do Paraná (UFPR), no Brasil, e da Universidade do Porto e da Universidade de Lisboa, em Portugal.

A pesquisa teve como objetivo analisar junto aos professores com expertise, que atuam na formação pedagógica de docentes universitários, a pertinência de propor os construtos, saberes e práticas que atendem ao paradigma da complexidade e a visão dialógica como pilares epistemológicos na ação docente, além da possibilidade de compartilhar suas experiências. Como objetivo geral, buscou-se investigar os construtos, saberes e práticas que caracterizam o paradigma da complexidade e a transdisciplinaridade como abordagens inovadoras na reconstrução da prática docente. Para seu alcance, elegeu-se como objetivo específico validar junto a pesquisadores com expertise em formação pedagógica a pertinên- 
cia do paradigma da complexidade, da transdisciplinaridade e da visão dialógica como postura epistemológica na ação docente. Já o problema central elaborado foi: como os docentes que atuam na formação pedagógica de professores universitários veem a pertinência de propor as concepções do paradigma da complexidade e da educação dialógica como pilares epistemológicos que sustentam a renovação da ação docente?

A metodologia da pesquisa caracterizou-se por uma abordagem qualitativa, do tipo etnográfica, com procedimentos via netnografia. Entende-se a netnografia como a liberdade de expressão criada na internet para oferecer aos pesquisadores a possibilidade de investigação e compartilhamento por meio de programas específicos e de levantamento de dados advindos dos envolvidos na pesquisa. Foi desenvolvida com a participação dos pesquisadores do PEFOP, que realizaram as entrevistas junto a 13 profissionais com expertise em diferentes instituições de ensino superior brasileiras e portuguesas. As entrevistas on-line foram gravadas e envolveram questões sobre como os participantes vêm desenvolvendo suas práticas e que opções epistemológicas caracterizam uma concepção inovadora na prática docente.

\section{Caminhos teóricos, epistemológicos e metodológicos}

O foco central da investigação foi buscar caminhos para superar a visão reducionista e compartimentalizada na educação, promulgada pelo pensamento newtoniano-cartesiano, desde o século XVII, que merece urgente repensar, em especial, devido às fragilidades emanadas desse paradigma simplificador (MORIN, 2000) focalizado na razão instrumental. A busca da superação da visão newtoniana-cartesiana é defendida por Capra (1997, 2002), pois ela vem imperando por 400 anos na ciência e, por consequência, na educação e não vem atendendo às exigências para formação da humanidade no século XXI. Nesse sentido, Guimarães (2020, p. 37) aponta a necessidade de desencadear uma discussão que envolva 
uma “[...] visão geral crítica da concepção instrumental, fragmentada e hierarquizada de homem, mundo e educação traçada a partir de uma interpretação mecanicista, utilitarista e, portanto, reducionista, da vida e da natureza".

As instituições de ensino, em especial, de educação superior, que se apresentam fragmentadas em áreas do conhecimento, em departamentos, acabam carregando uma visão reducionista e cartorial, inclusive brigando pelo conhecimento, pois cada curso se considera donatário. Esse processo de fragmentação e de disciplinarização exige uma mudança paradigmática que supere o método cartesiano de disjunção e separação. Como consequência do paradigma simplificador (MORIN, 2000, baseado na visão positivista e racional e na defesa das verdades absolutas e inquestionáveis, acabou-se focalizando a realidade objetiva e esse processo baseado na razão levou ao exílio do coração, da subjetividade, da amorosidade, essenciais para o desenvolvimento da condição humana.

Segundo Guimarães (2020, p. 289),

o modelo de exposição descontextualizada, ligado ao método cartesiano de fragmentação e compartimentalização do conhecimento, acaba por condicionar uma visão adaptada a recortes e reduções, especialmente às de aspecto quantitativo-estatísticos generalizante, embotando qualquer capacidade de apreensão dos aspectos interativos dos problemas mais abrangentes, incluindo as políticas públicas e demais ações de repercussões ambientais e globais.

O paradigma da ciência tem influência direta na educação; assim, as universidades, faculdades e escolas em geral necessitam abrir espaços para discussão dos professores para subsidiar a mudança paradigmática. Neste momento, os estudos têm apontado a pertinência de acolher autores como Morin (2000, 2011a, 2011b, 2014, 2015, 2021), quando propõe a visão da complexidade, e Freire $(1987,1992,1997,2011)$, que defende uma educação dialógica e transformadora. A aliança entre as propostas desses autores demanda o acolhimento de uma visão crítica, dialógica, complexa e significativa no ensinar e no aprender. 


\section{Visão da complexidade numa educação dialógica: as contribuições de Freire e Morin}

A busca por responder ao problema de pesquisa demandou longas discussões no PEFOP e contou com a colaboração de pesquisadores brasileiros e portugueses. Os estudos apontaram com ênfase, como autores fundamentais para uma mudança paradigmática, Paulo Freire e Edgar Morin. A vasta publicação deles levou a destacar, nos estudos de Freire, os livros Pedagogia da autonomia (2011), Pedagogia da esperança (1992) e Pedagogia do oprimido (1987) e, nos de Morin, as obras Os sete saberes necessários à educação do futuro (2000), A cabeça bem-feita: repensar a reforma, reformar o pensamento (2014) e A via para o futuro da bumanidade (2015). Esses educadores, icônicos, centenários e relevantes, se tornaram pertinentes na investigação, pois suas arrojadas propostas ainda demandam aplicação para alcançar uma educação que atenda aos anseios da sociedade no século XXI.

Na entrada do século XXI, esses autores centenários - Freire em função do centenário de nascimento e Morin em função do centenário de vida - vêm sendo colocados em evidência devido à grande relevância de suas abordagens epistemológicas para a educação.

\section{A educação dialógica de Freire}

O educador Paulo Reglus Neves Freire nasceu em Recife (PE), no dia 19 de setembro de 1921, e faleceu em 1997. No ano de 2021, comemora-se o centenário de seu nascimento no Brasil e em várias partes do mundo, pois, apesar de seu corpo ter morrido em 1997, suas ideias continuam vivas, atuais e pertinentes para subsidiar o movimento de mudança na educação. Sua vasta bibliografia foi traduzida em diversos idiomas, em especial, a obra Pedagogia do oprimido, que foi publicada em 37 idiomas e disseminada nos cinco continentes (GADOT'TI, 1996). A grande relevância dessa obra prende-se à denúncia de que na sociedade coexistem opressores e oprimidos e que a educação pode tornar-se um caminho de libertação dessa relação de poder. 
Freire lutou sua vida inteira contra a visão reducionista da educação bancária, na qual os professores acreditam que podem depositar conteúdos desconexos na cabeça dos alunos, mesmo que não façam sentido para os estudantes. No desafio da superação da visão bancária, conservadora e limitada, Freire (1992) defende uma educação envolvendo o diálogo, a aceitação dos diferentes, a inclusão e a luta pela justiça social; para tanto, propõe uma educação dialógica focalizada numa perspectiva crítica e autônoma, que gere uma formação de sujeitos capazes de transformar a visão política e social de suas realidades, considerando o estudante construtor de sua própria história.

Essa trajetória tem feito com que Freire seja um dos educadores mais traduzidos e lidos do mundo. Ele destaca a oralidade realizada por meio de diálogos críticos para tratar de liberdade, democracia e justiça, além de valorizar a palavra como condutora de superação de ideologias alienantes, tornando-se instrumento de uma transformação do homem e da sociedade.

No que refere aos saberes docentes propostos por Freire (2011), na obra Pedagogia da autonomia, torna-se um estudo imprescindível para a prática pedagógica transformadora, contemplando três grandes temas: (i) a prática docente e as reflexões exigidas do professor no processo de ensino, enfatizando que não há docência sem discência, ou seja, sem aprender ninguém ensina, caso contrário a prática docente culminaria na reprodução de conhecimento, em detrimento de sua produção, que necessita ser significativa e relevante na vida do aluno; (ii) a discussão sobre a concepção de que ensinar não é transferir conhecimento, à luz de que o ensino é inesgotável e construído pelo educando com a mediação do professor; (iii) a especificidade humana do ensino, como possibilidade de crescimento, desenvolvimento e expressão humana.

$\mathrm{O}$ autor defende, na mesma obra, que o ato de ensinar requer, além de muita pesquisa, respeito aos saberes dos educandos, que são definidos como "saberes socialmente construídos na prática comunitária” (FREIRE, 2011, p. 31). Para tanto, os docentes 
precisam "pensar certo, e saber que ensinar não é transferir conhecimento é fundamentalmente pensar certo, é uma postura exigente, difícil" (FREIRE, 2011, p. 48-49); nessa direção, desafia os docentes ao compromisso de exercer seu papel com consciência crítica diante dos outros e com os outros, em face do mundo e dos fatos.

A educação como uma ação potencialmente transformadora da realidade sempre foi defendida por Freire (2011), porém, para que seja possível educar com sabedoria, faz-se necessário apreender a realidade e as características do ambiente no qual se educa. Em sua visão, aprender ou ensinar algo se manifesta na legitimidade da postura e nos ideais que são adotados e apoiam toda a prática do professor, envolvendo seus educandos e o contexto social e histórico no qual ensina.

Uma educação que liberte implica a concepção ética do professor de que precisa considerar os interesses de seus alunos e buscar compreendê-los em sua essência, ajudando a superar seus desafios, valorizar suas potencialidades e sua visão de mundo, promovendo processos educativos que permitam o diálogo, a liberdade de expressão e a inclusão, em detrimento das propostas limitantes e os discursos preconceituosos que permeiam a práxis educativa.

\section{A visão da educação complexa de Morin}

Edgar Morin, pseudônimo de Edgar Nahoum, nasceu em Paris, em 1921. Judeu, formou-se em Direito, História e Geografia e realizou estudos em filosofia, sociologia e epistemologia e antropologia. Pesquisador emérito do Centre National de la Recherche Scientifique, sua principal obra, escrita durante muitos anos, especificamente, três décadas e meia, tendo sido iniciada em 1973, é constituída por seis volumes, sendo denominada La méthode ou, em português, $O$ método e considerada uma das maiores obras de epistemologia disponível. Morin publicou por volta de 45 livros e é considerado um dos principais pensadores contemporâneos e um dos principais teóricos sobre estudos da complexidade, defendendo em seus escritos o pensamento complexo ou paradigma da complexidade (MORIN, 2010). 
O ponto central em suas obras é a proposição da reforma do pensamento, por meio da mudança e da superação da concepção reducionista que acompanha a humanidade há 400 anos; para tanto, recomenda que a humanidade supere o paradigma da simplificação e busque o paradigma da complexidade. Na sua visão, o paradigma da complexidade envolve a formação para a cidadania, a aprendizagem para a vida, a educação solidária, em especial, a consciência planetária, com foco na sustentabilidade e na preservação do planeta, entre outros desafios.

Com esse desafio posto, Morin (2000) elaborou, a convite da Organização das Nações Unidas para a Educação, a Ciência e a Cultura (Unesco), a obra Os sete saberes necessários à educação do futuro, propondo, a partir de seu texto, construtos e fundamentos para que os profissionais da educação possam subsidiar a sua reforma do pensamento, isto é, organizar os conhecimentos para promover um ensino com visão mais ampla, significativa e transformadora. Essa obra de Morin é uma valiosa contribuição para a educação, estando presente em mais de 75 países e sendo uma indicação de leitura em diversos cursos de graduação e pós-graduação no Brasil. Os sete saberes que a compõem foram elaborados no sentido de possibilitar o ensinar a pensar, repensar e construir pensamentos para compreender a necessidade da religação, subsídios para enfrentar as dificuldades do processo educativo que são estruturadas na fragmentação dos conhecimentos e no parcelamento disciplinar.

Para considerar o pensamento da complexidade defendido por Morin (2000, p. 38), torna-se necessário entender a ideia de complexo:

\footnotetext{
Complexus significa o que foi tecido junto; de fato, há complexidade quando elementos diferentes são inseparáveis constitutivos do todo (econômico, o político, o sociológico, o psicológico, o afetivo, o mitológico), e há um tecido interdependente, interativo e inter-retroativo entre o objeto de conhecimento e seu contexto, as partes e o todo, o todo e as partes, as partes entre si. Por isso, a complexidade é a união entre a unidade e a multiplicidade.
}

Complexo provém de complectere, cuja raiz plectere significa trançar e enlaçar. Nessa concepção da complexidade, a educação 
assume a função de religar os conhecimentos que foram fragmentados em disciplinas isoladas, para que, assim, o ensino faça sentido e propicie ao aluno um encontro consigo mesmo, com o grupo e com a comunidade, aliando a razão e a emoção e passando a considerar os sentimentos de sensação, intuição, paixão, entre outros.

Um dos saberes que se destacam na obra de Morin (2000) trata do alerta sobre considerar o conhecimento pertinente, a ser proposto aos estudantes. Para isso, os professores precisam ter em mente a orientação de Morin (1993 apud PIMENTA, 1997, p. 8) de que

conhecimento não se reduz à informação. Esta é o primeiro estágio daquele. Conhecer implica um segundo estágio: o de trabalhar com as informações classificando-as, analisando-as e contextualizando-as. O terceiro estágio tem a ver com a inteligência, a consciência ou a sabedoria. Inteligência tem a ver com a arte de vincular o conhecimento de maneira útil e pertinente, isto é, de produzir formas de progresso e desenvolvimento; consciência e sabedoria envolvem reflexão, isto é, capacidade de produzir novas formas de existência, de humanização.

Os caminhos para refletir sobre essa indagação levam a se apropriar da visão de Morin (2014, p. 13) quando alerta:

Há inadequação cada vez mais ampla, profunda e grave entre saberes separados, fragmentados, compartilhados entre disciplinas, e, por outro lado, realidades ou problemas cada vez mais polidisciplinares, transversais, multidimensionais, transnacionais, globais e planetários.

A emergência se estende à consciência planetária, que, para Morin (2021), encontra no paradigma da complexidade a defesa para a formação para a cidadania, a aprendizagem para a vida, a educação solidária, em especial, com foco na sustentabilidade e na preservação do planeta, entre outros desafios.

\section{Diálogos e aproximações entre Freire e Morin}

As investigações do PEFOP permitiram perceber as convergências das visões de mundo de Morin e Freire, que podem ser 
vistas como mutuamente harmônicas e complementares, visto que as ideias defendem a trama entrelaçada dos fundamentos de uma nova visão para a educação complexa, transformadora, dialógica, sistêmica, multidimensional, sempre reflexiva e que considere as necessidades atuais das pessoas diante de uma educação cada vez mais técnica, reducionista, impessoal e mecanicista.

Trata-se de religar as dualidades originárias do pensar positivista, que gerou a imensa dificuldade de pensar de modo global, inter-relacional, unidimensional. Contemplar uma visão mais ampla implica buscar a reconexão ou religação entre razão-emoção, ciência-fé, existência-essência, sujeito-objeto, subjetividade-objetividade, alma-corpo, espírito-matéria, qualidade-quantidade, finalidade-causalidade, sentimento-razão, liberdade-determinismo, entre outras.

Outro ponto de convergência está na dimensão ética, pois os autores defendem uma educação que considere prioritariamente a dimensão humana, para além da técnica, desenvolvendo a amorosidade, o espírito de justiça, o respeito às pessoas e às coisas da natureza. Em Morin (2000), os conceitos de ética e moral não se separam, como tradicionalmente encontramos em outros autores, para os quais a ética regula as ações para uma convivência em harmonia, enquanto a moral é a ação que se realiza no sentido de viver bem com o outro. A visão da complexidade compreende e sempre articula os dois conceitos de modo uno e múltiplo, ao mesmo tempo.

O alcance da visão ética numa visão complexa exige o realinhamento da condição humana, pois o homem tornou-se equivocadamente o dono do universo, ignorando os outros seres, espécies e natureza. Nesse sentido, Morin (2021, p. 84) alerta para a necessidade do humanismo regenerado, entendido como aquele que

rejeita o humanismo de quase divinização do homem, voltado para a conquista e a dominação da natureza. Reconhece a complexidade humana, feita de contradições. O humanismo regenerado reconhece nossa animalidade e nosso cordão umbilical com a natureza, mas reconhece nossa especificidade intelectual e cultural. [...] o homem é ao mesmo tempo sapiens e demens, faber e mythologicus, economicus e ludens, ou seja, Homo complexus 
Ainda, a ética é fundamento de alerta de Morin (2000, p. 106) quando aponta desafios para o milênio, com uma missão baseada na antropoética, ou seja, trabalhar para humanizar a humanidade, efetuando "a dupla pilotagem do planeta: obedecer à vida, guiar a vida; alcançar a unidade planetária na diversidade", o que exige respeitar no outro sua diferença e sua identidade, implicando, ao mesmo tempo, respeitar a si mesmo. Sabiamente, recomenda aos professores o desenvolvimento da ética da solidariedade, da compreensão, da compaixão, da paixão, da poesia, a fim de enfrentar a missão de ensinar a ética do gênero humano, a qual define homens e mulheres como partícipes do planeta e não como donos dele.

$\mathrm{Na}$ mesma direção, o pensamento de Freire (2011, p. 93) aponta a dimensão ética como indispensável à prática docente, acrescentando "o saber da impossibilidade de desunir o ensino dos conteúdos da formação ética dos educandos"; assim, defende a autoridade pela competência e não pela opressão, assim como a liberdade como forma de expressão da humanidade, por meio do diálogo de iguais.

Amorosidade é a palavra que dimensiona o papel ético de Freire na humanidade. Compreensivo e preocupado com os caminhos da sociedade, lutou por justiça e foi exilado por seus ideais durante a ditadura, que exigiu sua saída do Brasil, mas permitiu a sua inserção nos cinco continentes, por sua fala e por sua obra, nas quais defende os oprimidos, denuncia as repressões, a falta de consideração com os seres humanos, com foco na luta, no anúncio e na denúncia pela conquista dos direitos à terra, à moradia, à alimentação e à educação de qualidade, pois, em seu dizer, a educação liberta.

O entrelaçamento das ideias desses autores demanda um movimento de reencontro da humanidade, o que requer respeitar a si mesmo e os outros seres como seus semelhantes e reconhecer o direito de viver em plenitude no planeta, demandando processos educativos que contemplem a ecologia da ação, que se faz ao caminhar para uma nova via, a qual envolve sustentabilidade e ser 
solidário no/em/com o planeta, responsabilizando-se pela preservação da natureza e pela comunhão englobante com a terra pátria.

\section{Análise e discussão dos dados}

A investigação empreendida, do tipo etnográfica, teve como objetivos investigar os construtos, saberes e práticas que caracterizam o paradigma da complexidade e a transdisciplinaridade como abordagens inovadoras na reconstrução da prática docente e validar junto a pesquisadores com expertise em formação pedagógica a pertinência do paradigma da complexidade, da transdisciplinaridade e da visão dialógica como postura epistemológica na ação docente.

A técnica de coleta de informações escolhida foi a entrevista, realizada de forma on-line, caracterizando-se por permitir obter dados do entrevistado por meio da manifestação pessoal. Segundo Minayo (1992, p. 57), a entrevista “[...] não é uma conversa despretensiosa e neutra, uma vez que se insere como meio de coleta dos fatos relatados pelos atores, enquanto sujeitos objeto da pesquisa que vivenciam uma determinada realidade que está sendo focalizada". Apesar de a entrevista buscar a objetividade, a base metodológica da complexidade (MORAES; VALENTE, 2008) permite reconhecer a subjetividade dos sujeitos da pesquisa, identificando seus limites, como também as incertezas e as descontinuidades na sua maneira de pensar e agir.

Para realizar as entrevistas, foi estruturado um documento orientador dividido em blocos (Quadro 1), cada qual com pequenos textos explicativos, denominados "Contextualização", com a finalidade de estabelecer um contexto para as perguntas orientadoras. Os blocos foram desenvolvidos de maneira a coletar dados a partir das narrativas dos pesquisados, para buscar possíveis respostas aos objetivos da pesquisa. 


\section{Quadro 1 - Tópicos orientadores da entrevista}

\section{Bloco 1 - Conhecimento teórico e prático da complexidade e transdisci- plinaridade de Morin e da educação transformadora de Freire}

Contextualização: $\mathrm{O}$ paradigma newtoniano-cartesiano promulgou a visão racional e objetiva, gerando um posicionamento reducionista frente aos fenômenos do universo. Para que os professores e outros profissionais abandonem a visão sectária e racional, há necessidade de transpor as gaiolas epistemológicas compartimentalizadas criadas pela abordagem conservadora desde o século XVII, que merece ser superada. Nesse sentido, gostaríamos de conhecer suas aproximações/entendimentos com relação à teoria da complexidade de Edgar Morin e sua aplicabilidade prática no pensamento complexo e transdisciplinar, aliado à sua impressão sobre a educação transformadora de Paulo Freire.

\section{Questionamentos:}

1- Com relação aos seus conhecimentos, quais construtos do pensamento complexo e transdisciplinar de Edgar Morin auxiliam na construção da postura epistemológica da ação docente do professor formador com vistas à reconstrução da prática pedagógica sob o olhar inovador da educação?

2- A partir de seus saberes sobre a educação transformadora de Paulo Freire, quais fundamentos dessa visão contribuem na construção e na produção do conhecimento do professor formador para que desenvolva uma postura crítica, criativa e transformadora que poderá nutrir sua prática pedagógica? Para responder, utilize palavras-chave que mostrem a aproximação entre o pensamento complexo e a educação transformadora.

\section{Bloco 2 - Saberes, construtos e práticas do campo didático-pedagógico} que estruturam a formação de docentes

Contextualização: Vamos supor que você, professor, foi convidado para ministrar um curso de formação didático-pedagógica para acadêmicos que estão se preparando para atuar com a educação superior. Sua responsabilidade é construir uma proposta que contenha todos os construtos, saberes e práticas pertinentes à formação docente que respondam às inovações pedagógicas frente aos desafios epistemológicos e culturais da contemporaneidade.

Questionamento: A partir de seus conhecimentos sobre o pensamento complexo e a educação transformadora, como você comporia uma proposta de formação pedagógica, ou seja, que elementos/construtos/saberes não poderiam deixar de ser oferecidos para subsidiar a proposição de uma docência crítica, reflexiva, complexa e transformadora?

Fonte: As autoras (2021). 
Para responder aos objetivos propostos para este artigo, foram selecionados alguns dados dos 13 professores participantes, presentes nos blocos 1 e 2 e registrados por meio das respostas aos questionamentos. Para salvaguardar o anonimato dos participantes, utilizamos a letra P para os participantes portugueses e B para os brasileiros.

Sobre as ideias-conceito da complexidade de Morin que podem contribuir epistemologicamente com o professor formador com vistas à reconstrução da prática pedagógica sob o olhar inovador da educação, dois participantes fizeram a correlação da complexidade com o respeito:

Esta teoria faz com que o professor olhe o estudante como um ser em desenvolvimento e com potencialidades únicas para aprender (B1).

A complexidade leva a compreensão, a respeitar cada aluno, assim como o grupo de estudante, como ser humano que busca o seu desenvolvimento dentro do seu tempo e possibilidade (B2).

Nesse sentido, Morin (2000, p. 106) alerta sobre a necessidade de "respeitar no outro, ao mesmo tempo, a diferença e a identidade quanto a si mesmo".

Ainda sobre o pensamento complexo, um participante citou a formação humana como base para a prática pedagógica inovadora; para ele, "o pensamento complexo possibilita rever os conbecimentos sobre o processo de ensino, indo além do desenvolvimento de conteúdo específicos, mas fundamentalmente buscar a formação do ser humano, uma formação integral' (P4).

Os setes saberes propostos por Morin (2000, p. 55) apontam que "compreender o humano é compreender sua unidade na diversidade, sua diversidade na unidade. É preciso conceber a unidade do múltiplo, a multiplicidade do uno". Dessa maneira, os professores podem entender que o pensamento e as ações pedagógicas devem ser capazes de respeitar as diferenças, reconhecendo a unidade, a diversidade, a sensibilidade, a emoção de cada aluno.

O pensamento complexo também alerta sobre a necessidade de superar o paradigma da simplificação, estruturado na fragmentação, na disjunção, na visão linear e unidimensional, que impos- 
sibilita estabelecer relações entre as partes e o todo e vice-versa, desconsiderando a multidimensionalidade dos fenômenos e sua complexidade, conduzindo à uma inteligência cega. É necessária a reforma do pensamento para reconstruir a educação que conduza para o bem pensar.

Sobre essa ideia-conceito de Morin, três professores citaram a superação de fundamentos epistemológicos e metodológicos da prática pedagógica que ainda são estruturados nos construtos da ciência moderna de modelo racionalista:

\begin{abstract}
Primeiro eu acho que estudar o pensamento de Edgar Morin é uma mudança de vida, você nunca mais olha nada na sua vida de uma forma linear, tudo que você passa na vida não só dentro da sala de aula, na sua profissão como professor, mas na sua própria vida você aprende que existem muitas formas de ver uma mesma coisa, a vida tem muitos jeitos de ser, depende do jeito que a gente vê e eu acho que esse para mim é o maior ensinamento (P6).

O que Morin demonstra é a ruptura com velhos modelos educativos e a construção, tessitura de novas formas de desenvolver os processos educativos, levando-se em conta os atores envolvidos nas teias de relações (B3).

Os professores precisam ter essa ideia de rede, abandonar a ideia disciplinar porque a disciplina sożinha não dá mais conta de responder as questões da sociedade atual (B4).
\end{abstract}

Quanto ao conhecimento dos pesquisados sobre a contribuição da educação transformadora de Freire na prática pedagógica, identificou-se a preocupação com o respeito aos estudantes:

Ele nos ensinou o respeito mútuo, a superação do egoísmo, o olhar para o outro de maneira que possamos não apenas fazer com que os alunos aprendam os conteúdos escolares, como uma educação bancária, mas que o processo de ensino aprendizagem contribua para o desenvolvimento de cidadãos que estejam prontos para enfrentar os desafios da sociedade (B2).

Ele nos ensinou a respeitar o aluno, a contextualizar, desenvolver um processo de ensino aprendizagem que considere e respeite os conhecimentos prévios, as experiências, que o estudante tem, para que a aprendizagem seja significativa (B3).

No livro Pedagogia da autonomia, Freire (2011) fala sobre o respeito, relacionando aos saberes do educando, à dignidade e autono- 
mia, ao conhecimento de senso comum, à identidade, à dignidade, à curiosidade, à timidez, enfim, desafia a lutar contra qualquer forma de desrespeito; cabe compreender que o ser humano não está pronto, mas se desenvolve ao longo da vida, necessitando ter clareza do seu inacabamento e, como recomenda Freire (1997), procurar oferecer caminhos para sua transformação contínua.

A educação transformadora mostra que a formação docente precisa ser permeada pelo exercício da criticidade, que "implica a promoção da curiosidade ingênua à curiosidade epistemológica, e do outro, sem o reconhecimento do valor das emoções, da sensibilidade, da afetividade, da intuição ou adivinhação" (FREIRE, 2011, p. 20). Nessa direção, os participantes identificaram a necessidade de desenvolver e trabalhar com a criticidade:

A promoção da voz ativa dos alunos, concebendo-os como agentes críticos, a partir do diálogo argumentativo (P1).

Consciencialização do papel da educação e do educador na estruturação de ferramentas que permitam aos alunos assumir uma postura crítica, esclarecida e questionadora perante a realidade que os rodeia, ou seja, transformarem-se em cidadãos ativos e conscientes, mais bem apetrechados para lidar com a realidade política, social, mediática, etc. (P3).

Identificou-se, nos relatos dos professores, que é possível, por meio da educação transformadora proposta por Freire, compreender alguns alicerces fundamentais para uma educação crítica, reflexiva e inovadora, uma vez que esse grande pensador recomenda em suas obras a necessidade de respeitar o outro, reconhecer a alteridade, considerar o sujeito histórico, buscar considerar os valores e o posicionamento ético, a formação para a cidadania, o estímulo à curiosidade epistemológica dos alunos. Para tanto, cabe aos professores identificar que educar é um ato político e que, para construir uma educação/formação nessa direção, é preciso trabalhar simultaneamente o amor e a rigorosidade metódica, para que os educandos possam “se 'aproximar' dos objetos cognoscíveis. E esta rigorosidade metódica não tem nada que ver com o discurso 'bancário' meramente transferidor do perfil do objeto ou do con- 
teúdo" (FREIRE, 2011, p. 13). O participante B3 complementou essa ideia da seguinte forma:

Eu acho que um vínculo muito mais forte do que simplesmente a transmissão do conhecimento, daquele professor que tem o papel que ensina conteúdo, uma educação bancária, numa relação mais horizontal é o que Freire nos deixa como legado é que os indivíduos aprendem na troca, na relação, na interação daquele que aprende com o outro e aprende com seus próprios alunos, que teoricamente este sabe menos que o professor. Acho primordial em Paulo Freire e sua proposta de diálogo respeitoso, aberto ao debate, saber ouvir o outro, entender a questão da alteridade, de se colocar no lugar daquele que está ali naquele confronto. Como ele fala rigor, mas ao mesmo tempo com amorosidade.

Ao longo da pesquisa, foram observadas muitas aproximações e complementaridades em Freire e Morin, assim como alguns distanciamentos. De fato, são teorias desenvolvidas em contextos e países diferentes, tempos e espaços diferenciados, objetivos distintos, porém convergem no tocante à visão de pensar a educação de maneira a superar o paradigma conservador que norteia a prática pedagógica.

Algumas aproximações desses autores, segundo Behrens e Prigol (2020, p. 20), se referem ao docente, "como a importância da ética, da afetividade e da visão multidimensional da realidade", além de se dar "na contextualização, na aprendizagem de coparticipação, para que os conteúdos superem a superficialidade para serem significativos para a vida". Para ampliar essas aproximações, foi solicitado aos participantes que elencassem algumas palavras que as mostrassem, possibilitando a construção de uma nuvem de palavras (Figura 1). 


\section{DiálConsciência Humanidade EducaçãoBancária

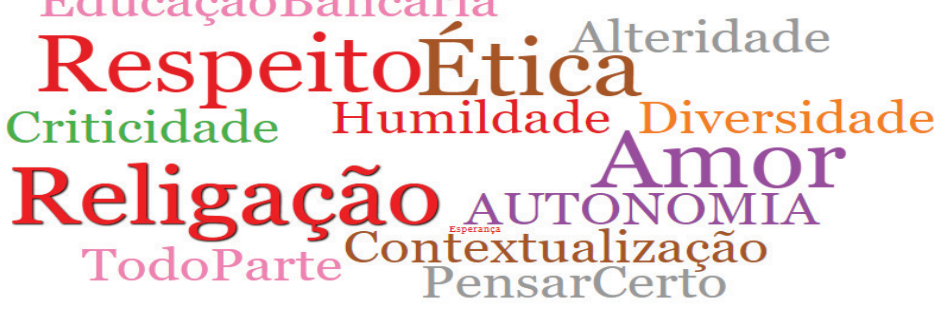

Figura 1 - Palavras aproximadoras entre Morin e Freire, de acordo com os pesquisados

Fonte: As autoras (2021).

Além dessa nuvem de palavras, surgiram considerações dos pesquisados a partir de seus conhecimentos sobre o pensamento complexo e a educação transformadora relacionados à composição de uma proposta de formação pedagógica, apresentando elementos/construtos/ saberes que subsidiassem a proposição de uma docência crítica, reflexiva, complexa e transformadora. As diversas sugestões possibilitaram organizar o Quadro 2.

Nessa seleção de ideias, pode-se observar a preocupação dos participantes com a necessidade de superação do paradigma cartesiano, que induz ao pensamento fragmentado, reducionista, que caracterizou a prática pedagógica nos últimos 400 anos, focalizada na reprodução do conhecimento, na simplificação e na visão unidimensional.

Igualmente, os participantes sinalizaram o reconhecimento do embate entre a teoria e a prática, a metodologia e o conteúdo, que merece urgente mudança e transformação. As manifestações dos pesquisados, ou seja, dos professores com expertise, já apresentam contribuições que avançam para a urgência da mudança de paradigma na educação, de forma a atender aos anseios da sociedade no século XXI. Trata-se da relevância da aliança entre a educação dialógica e a visão complexa, apontando avanços no sentido 
de superação da dualidade entre razão e emoção, acrescentando à formação docente um olhar para o indivíduo, a sociedade e natureza, compreendendo a importância da multidimensionalidade no processo educativo.

Quadro 2 - Propostas para uma formação pedagógica,
crítica, reflexiva, complexa e transformadora

\begin{tabular}{|l|c|}
\hline \multicolumn{1}{|c|}{ Proposta } & Classificação \\
\hline $\begin{array}{l}\text { "Desenvolvimento de estratégias e experiências pedagó- } \\
\text { gicas que promovam o desenvolvimento de espirito critico } \\
\text { junto dos diversos públicos escolares" (P3). }\end{array}$ & Metodologia \\
\hline $\begin{array}{l}\text { "Um curso que prepare o professor para a multiplicidade } \\
\text { de olhares, ir além de entender a inclusão de pessoas com } \\
\text { deficiências, mas a relação entre os indivíduos" (P5). }\end{array}$ & Respeito \\
\hline $\begin{array}{l}\text { "Respeitar as individualidades, mas entender que aquele } \\
\text { sujeito tem saberes, têm comportamentos, tem uma postu- } \\
\text { ra que foi construída ao longo de toda a sua vida" (B2). }\end{array}$ & Respeito \\
\hline $\begin{array}{l}\text { "Não é só o professor que tem que ensinar, ele tem coisas } \\
\text { a aprender com o estudante" (P2). }\end{array}$ & Aprendente \\
\hline $\begin{array}{l}\text { "Ter coerência entre teoria e prática, em função dos gran- } \\
\text { des disparates que nós temos hoje nas propostas de forma- } \\
\text { ção de professores, focalizada só na teoria e distantes da } \\
\text { realidade da escola" (P5). }\end{array}$ & \\
\hline $\begin{array}{l}\text { "Consciência de seu papel social e transformador da so- } \\
\text { ciedade, para que seja expurgado tal modelo retrógrado e } \\
\text { ultrapassado" (B1). }\end{array}$ & Papel social \\
\hline $\begin{array}{l}\text { "Eu teria muito a base em CTS (Ciência, Tecnologia e So- } \\
\text { ciedade) em relação a questionar o modelo de ciência que } \\
\text { temos, as verdades científicas, em buscar ser critico em } \\
\text { relação aos conteúdos que nos são impostos" (B3). }\end{array}$ & paradigmas \\
\hline $\begin{array}{l}\text { "Pensar em uma formação na qual o professor compreen- } \\
\text { da a relação entre o aluno, os conteúdos, a vida e a natu- } \\
\text { reza, para buscar uma educação integral" (P1). }\end{array}$ & Educação \\
integral \\
\hline
\end{tabular}

Fonte: As autoras (2021). 


\section{Considerações finais}

Os avanços na pesquisa com docentes brasileiros e portugueses com expertise em formação pedagógica de professores permitiram ao PEFOP realizar discussões e reflexões que apontaram para a convergência com o alerta de Morin, Ciurana e Motta (2003, p. 110) de que os fundamentos, saberes e construtos presentes na educação dialógica e complexa não podem ser implementados sem a compreensão "[...] de que o devir planetário da humanidade e a emergência de uma sociedade mundo estão marcados pela incerteza. A incerteza, porém, requisita a esperança. A incerteza requer complexificar nossa itinerância com uma dialógica entre desesperança e esperança". Trata-se de mobilizar a esperança em um mundo mais justo e igualitário, fraterno e solidário, no qual o pensamento complexo e dialógico permita enfrentar os problemas, que implicam incertezas e imprevisibilidades, mas podem, com visão crítica e reflexiva, impulsionar a responsabilidade social de extensão planetária, ultrapassando o modelo hegemônico dos masculinos, adultos, técnicos, ocidentais e passando a considerar o movimento civilizatório de inclusão dos femininos, juvenis, idosos, multiétnicos e multiculturais (MORIN; CIURANA; MOTTA, 2003).

Os movimentos multiculturais do patrimônio humano podem mudar o mundo, como ensinou Freire; para tanto, a humanidade precisa acreditar nas utopias e nos sonhos possíveis. Para os autores analisados, a educação é o caminho para a transformação e para atingir a consciência planetária; assim, a humanidade precisa superar as ortodoxias religiosas, políticas e econômicas, que tanto afetam os países e as populações, em especial, com movimentos mundiais que acolham os menos favorecidos, independentemente de raça, gênero, religião, etnia, entre outros preconceitos.

Acredita-se que a relevância e pertinência dos estudos desses educadores centenários acentuaram-se no século XXI, em função da preocupação de ambos na focalização de humanizar a humanidade, por meio da busca pela essência humana, do encontro consigo mesmo, com sua comunidade e seu planeta, de viver com significado à procura da felicidade, da alegria e da poesia da vida. 


\section{Referências}

BEHRENS, Marilda Aparecida; PRIGOL, Edna Liz. Avanços do pensamento complexo na visão ética. DEBATES EM EDUCAÇÃO. v.12, p.724 - 738, 2020.

CAPRA, Fritjof. A teia da vida: uma nova compreensão científica dos sistemas vivos. São Paulo: Cultrix, 1997.

CAPRA, Fritjof. As conexões ocultas: ciência para uma vida sustentável. São Paulo: Cultrix, 2002.

FREIRE, Paulo. Pedagogia do oprimido. Rio de Janeiro: Paz e Terra, 1987.

FREIRE, Paulo. Pedagogia da esperança. Rio de Janeiro: Paz e Terra, 1992.

FREIRE, Paulo. Pedagogia da indignação: cartas pedagógicas e outros escritos. São Paulo: Editora UNESP, 1997.

FREIRE, Paulo. Pedagogia da autonomia: saberes necessários à prática educativa. São Paulo: Paz e Terra, 2011.

GADOT'TI, Moacir. Apresentação. In: GADOTI, Moacir (Org.). Paulo Freire: uma biobibliografia. São Paulo: Cortez, 1996.

GUIMARÃES, Carlos Antonio Fragoso. Paulo Freire e Edgar Morin: sobre saberes, paradigmas e educação - um diálogo epistemológico. Curitiba: Appris, 2020.

MORAES, M. C \& VALENTE, J. A. Como pesquisar em Educação a partir da complexidade e da transdisciplinaridade? São Paulo, SP: Paulus, 2008.

MINAYO, M. C. S. O Desafio do Conhecimento. São Paulo: Hucitec, 1992.

MORIN, Edgar. Os sete saberes necessários à educação do futuro. 3. ed. São Paulo: Cortez; Brasília, DF: Unesco, 2000.

MORIN, Edgar. Meu caminho. Rio de janeiro: Bertrand Brasil, 2010.

MORIN, Edgar. Rumo ao abismo. Rio de Janeiro: Bertrand Brasil, 2011 a.

MORIN, Edgar. Introdução ao pensamento complexo. 4. ed. Porto Alegre: Sulina, 2011b.

MORIN, Edgar. A cabeça bem-feita: repensar a reforma, reformar o pensamento. 22. ed. Rio de Janeiro: Bertrand Brasil, 2014. 
MORIN, Edgar. A via para o futuro da humanidade. Rio de Janeiro: Bertrand Brasil, 2015.

MORIN, Edgar. É hora de mudarmos de via: lições de coronavírus. 2. ed. Rio de Janeiro: Bertrand Brasil, 2021.

MORIN, Edgar; CIURANA, Emilio Roger; MOT'TA, Raúl Domingo. Educar na era planetária: o pensamento complexo como método de aprendizagem no erro e na incerteza humana. São Paulo: Cortez, 2003.

PIMENTA, Selma. Formação de professores: saberes da docência e identidade do professor. Nuances, São Paulo, v. 3, n. 3, p. 5-14, 1997. Disponível em: https:// revista.fct.unesp.br/index.php/Nuances/article/view/50. Acesso em: 16 ago. 2021. 